\title{
INVENTARIO DE BIENES DE JUAN MARTÍNEZ, ESCRIBANO PÚBLICO DE JEREZ DE LA FRONTERA EN LA PRIMERA MITAD DEL SIGLO XV.
}

\author{
INVENTORY OF ASSETS OF JUAN MARTINEZ, NOTARY PUBLIC OF \\ JEREZ DE LA FRONTERA, DURING THE FIRST HALF OF THE $15^{\mathrm{TH}}$ \\ CENTURY.
}

\author{
Ma Belén Piqueras García \\ Universidad de Cádiz \\ belen.piqueras@uca.es
}

RESUMEN: El presente estudio se centra en el análisis del Inventario de bienes de Juan Martínez, escribano de Jerez de la Frontera durante la primera mitad del siglo XV; Persiguiendo sacar a la luz este documento de tipo notarial, hasta ahora inédito, del que abordamos su contenido y análisis diplomático.

Palabras Clave: Diplomática, Documento, Escribano público, Historia, Edad Media.

ABSTRACT: The present study is centered in the analysis of the Inventory of valuable objects of Juan Martínez, Jerez de la Frontera notary public during the first half of 15th century; Persecuting to bring to light this document from notarial type, until now unpublished, that approached its content and diplomatic analysis.

KeYwords: Diplomatic, Document, Notary, History, Middle Ages. 


\section{INTRODUCCIÓN}

El estudio que presentamos se centra en el Inventario de bienes de Juan Martínez, a través de la documentación conservada en el Archivo de la Real Chancillería de Granada ${ }^{1}$, dentro de la colección de documentos manuscritos, pergaminos, de dicho Archivo ${ }^{2}$.

Tiene como objetivo sacar a la luz este documento que, relativo al personaje mencionado, sería realizado tras su muerte, siguiendo las disposiciones indicadas por él y confirmadas por su esposa, Catalina Sánchez, en sus testamentos.

El inventario post mortem de los bienes de Juan Martínez, escribano público del número de Jerez de la Frontera, fue realizado, a petición de sus herederos, ante Gonzalo Román, escribano público de dicha localidad, el día 24 de enero de 1459, quien lo valida con su signo, ante la presencia del alcalde, Diego Romi, y cuatro testigos, todos ellos escribanos. Siendo fechado, bastantes años después, en la audiencia de Granada el 15 de julio de 1550, por Antón Pérez oidor de su parte con petición.

Su contenido, al desvelar datos sobre bienes pertenecientes a este escribano jerezano, contribuye sin duda, y aunque sea someramente, al conocimiento de algunas de sus circunstancias, máxime cuando en el Archivo de Protocolos no se conserva su testamento, y las noticias recogidas sobre él en las Actas Capitulares son también exiguas. No obstante sumando los datos que encierran cada una de las fuentes aludidas y consultadas, de manera complementaria, junto con los datos aportados por la bibliografía revisada, podremos conocer algunos detalles, repetimos, exiguos, pero hasta ahora inéditos ${ }^{3}$. Además perseguimos poner de manifiesto la relevancia de este tipo de documento notarial que, al desvelar las

1. En adelante ARCHGR.

2. Incluido en el Catálogo publicado por Maj. MÁRTIR ALARIO. Catálogo de la Colección de pergaminos del Archivo de la Real Chancillería de Granada. Junta de Andalucía, Consejería de Cultura, 2009. ES.18087.ARCHGR/060CDMA. Colección de documentos manuscritos. Pergamino nº 191.

3. Datos que quizás podrán sumarse en su momento y en su medida, a la hora de realizar algún nuevo estudio sobre los escribanos públicos jerezanos a finales de la Edad Media, en el tránsito a la modernidad, o sobre documentación notarial de Jerez de la Frontera en el periodo indicado. Al respecto son de obligada cita y consulta, además de los estudios de carácter general sobre los escribanos de concejo, por ejemplo para Castilla: E. CORRAL GARCÍA. El escribano de concejo en la Corona de Castilla (Siglos XI-XVIII), Burgos, 1987. O F. ARRIBAS ARRANZ. "Los escribanos públicos en Castilla durante el siglo XV", Centenario de la Ley de Notariado, Sección primera, Estudios Históricos, I, (Madrid, 1964), pp. 244-249. Otros, dedicados a comunidades o localidades de éstas, como P. OSTOS SALCEDO. "Los escribanos públicos de Córdoba en el tránsito de la Edad Media a la Edad Moderna. Una aproximación", El Notariado andaluz en el tránsito de la Edad Media a la Moderna (Sevilla, 1995), pp. 171-256. M.L. PARDO RODRÍGUEZ. "La escribanía mayor del concejo de Sevilla en la Edad Media", La Diplomatique urbaine en Europe en Moyen Âge (Garant, 2000), pp. 357-381. O, para el caso concreto de Cádiz, los exhaustivos trabajos hasta ahora realizados por MªD. ROJAS VACA. entre ellos, "Notariado público y Documento Notarial en Jerez de la Frontera en el tránsito a la Modernidad", en El Notariado andaluz en el tránsito de la Edad Media a la Edad Moderna, I Jornadas sobre el Notariado en Andalucía, (Sevilla, 1995), pp. 293-338. "Los escribanos de concejo en Cádiz (1557-1607)", HID 24 (Sevilla, 1997), pp. 429-448, "Las escribanías del cabildo Municipal en Jerez de la Frontera (1514-1615)", HID 37 (Sevilla, 2010), pp. 283-336. 
pertenencias de determinadas personas, contribuye al conocimiento parcial de sus propietarios, suponiendo, en palabras de Tomás Faci, la representación material de una identidad social ${ }^{4}$.

El documento lo anexamos como Apéndice Documental, transcribiéndolo íntegramente, facilitando su posterior lectura, e incluyendo su imagen original, tal y como se conserva y reproduce en el Archivo y Catálogo de pergaminos, anteriormente aludidos.

\section{LOS INVENTARIOS}

Este tipo documental queda incluido, diplomáticamente hablando, y como ya venimos reiterando, dentro de la tipología de documentación notarial. Utilizando las palabras de Ángel Riesco Terrero, quedan englobados como apéndice del derecho hereditario ${ }^{5}$. En los protocolos notariales encontramos anotados testamentos, codicilos, pero además también hay que citar otra serie de liberalidades mortis causa, entre ellas los inventarios e inventarios post mortem.

Desde el punto de vista de la Diplomática y del Derecho, es un instrumento jurídico-diplomático de carácter descriptivo e identificativo. Su discurso contempla la enumeración de bienes, de diversa tipología, pertenecientes a una persona particular, familia o institución, llegando a convertirse en elemento testimonial y probatorio 6

Podían ser realizados a tenor de diferentes situaciones: dotes matrimoniales, embargos judiciales, repartos de herencia, etc. Aunque la práctica al respecto lleva a la conclusión de que los más abundantes son los realizados tras el fallecimiento de sus propietarios. Su factura garantizaba la integridad del legado transmitido a los herederos, ya que en ellos se relacionan detalladamente los bienes muebles o inmuebles, o bien ambos, de una persona. Siendo expedidos públicamente ante el notario, constituyendo pues un acto jurídico de garantía, al certificar éste la veracidad de los datos aportados. Además en su realización estarían presentes los representantes familiares.

4. G. TOMÁS FACI. "Distinción social en el seno de la Baja Nobleza aragonesa. El palacio de los Zapata de Calatayud en 1984", Anuario de Estudios Medievales 39/2, ( julio-diciembre, 2009), pp. 605-629.

5. A. RIESCO TERRERO. "Notariado y Documentación notarial castellano-leonesa de los siglos X-XIII", I Jornadas sobre Documentación jurídico-administrativa, económico-financiera y judicial del reino castellano leonés (s. X-XIII), (Madrid, febrero-marzo, 2002), p. 151. Engloba con esta denominación a deslindes, particiones de herencia, bienes y sucesiones, carta de revocación total o parcial de últimas voluntades, aceptación, renunciación de herencia, inventarios, etc. De este mismo autor, y sobre temática similar, puede consultarse "El Notariado castellano bajomedieval (siglos XIV-XV): Historia de esta institución y de la producción documental de los Notarios hasta el Reinado de Isabel I de Castilla", Segundas Jornadas cientificas sobre documentación de la Corona de Castilla (siglos XIII-XV), (Madrid, 2003), pp. 175-224.

6. Definición dada por A. RIESCO TERRERO. Vocabulario científico-técnico de Paleografía, Diplomática y ciencias afines. Madrid, Barrezo \& Azedo Ediciones, 2003, p. 220. 
Aunque eran más frecuentes en caso de legados de grandes patrimonios, se constata su frecuente emisión aún en familias de no demasiada solvencia patrimonial.

Los inventarios o recuentos de bienes contribuyen pues al conocimiento de las condiciones materiales en que vivían sus protagonistas, constituyendo una fuente notarial importantísima para el estudio de la cultura material de las poblaciones, de la realidad cotidiana, de la historia rural etc. En resumen una fuente rica en información ${ }^{7}$. No obstante presentan notables variaciones en su tipología, en base a la información en ellos contenida. Al respecto Hortensio Sobrado Correa en su artículo sobre los inventarios post-mortem alude a lo dicho por Micheline Baulant: Un inventario ideal tendría que tener varias cualidades básicas: ser exhaustivo, preciso, exacto, detallado y con evaluación del valor de los objetos que describe ${ }^{8}$.

Sin embargo, en la práctica, esas cualidades son inexistentes en la mayoría de ellos, incluyendo algunos una gran riqueza de datos, y otros, por contra, deficiencias y omisiones. Ello conduce a que se les tache de falta de representatividad y fiabilidad en el recuento de bienes, en la información que encierran. ${ }^{9}$.

Su realización, situándonos en el contexto de la Edad Media, denota en principio la pertenencia a un grupo social destacado, a una situación "privilegiada". Si se hacía un inventario era porque se tenían bienes que inventariar ${ }^{10}$, contando además con que su factura conllevaba el pago de las tasas correspondientes al escribano que hacía el asiento, que sin duda podían escapar de las posibilidades de algunos jerezanos del momento. A ellas aluden las ordenanzas que, de los siglos XV y XVI, se conservan en Jerez de la Frontera ${ }^{11}$. En concreto en el capítulo VIII, referido a disposiciones concernientes sobre el escribano de cabildo y los escribanos públicos, quedan detalladas las tasas por la realización de inventarios ${ }^{12}$ :

7. En este sentido apuntaron en su momento en las I Jornadas aplicadas de las ciencias históricas, celebradas en Santiago de Compostela en 1973. Años después, también en Santiago, 1982, se celebraría un Coloquio de Metodología Histórica aplicada. La Documentación Notarial y la Historia. En ambas ocasiones se incidió en la importancia de la documentación notarial, y, entre ella, de los inventarios.

8. H. SOBRADO CORREA. "Los inventarios post-mortem", en Hispania LXIII/3, no 215 (2003), pp. 825-862.

9. A pesar de ello resulta innegable la variedad de estudios a realizar, tomando como base este tipo de fuente documental. Por ejemplo podemos aludir al estudio realizado por G. CAÑADAS DE LA FUENTE y otros, sobre "Los Inventarios como fuente para la historia de las Ciencias de la Salud", III Jornadas de la Sociedad Española de Ciencias y Técnicas Historiográficas, Diplomática antigua. Diplomática moderna, (Murcia, 20 y 21 de junio de 2005), pp. 257-266.

10. Además en este caso el inventario corresponde a los bienes de un escribano, los cuales formaban parte de la "élite" de la sociedad del momento. Sobre la formación de la oligarquía jerezana puede consultarse el estudio realizado por E.J. RUIZ PILARES. "La formación de la oligarquía jerezana y la patrimonialización de los oficios concejiles (siglos XIII al XV)", en Revista de Historia de Jerez 16/17 (2010/2012), pp. 1-10.

11. Publicadas por MaA. CARMONA RUIZ y E. MARTÍN GUTIÉRREZ. Recopilación de las ordenanzas del concejo de Xerez de la Frontera. Siglos XV-XVI. Universidad de Cádiz, 2010.

12. Concretamente en el epígrafe 8, del cap. VIII, de la citada obra: Recopilación de las ordenanzas..., pp. 112- 122 . 
De un ynventario en que ubiere una hoja de papel de ambas partes, treinta maravedis. Si oviere un pliego quarenta maravedis e por cada hoja al respeto de veynte maravedis ${ }^{13}$.

De ynbentario en oviere vna foja de papel de anvas partes veynte maravedis.

$Y$ si ouiere más de un pliego quarenta maravedís, diez por cada hoja al respeto de veynte maravedis ${ }^{14}$.

Centrándonos en el que nos ocupa ${ }^{15}$, podemos hacer un promedio según la variación de las tasas entre 1484 y 1490, fechas de estas disposiciones, calculando que su expedición pudo oscilar entre 60 y 90 maravedís.

\section{InVEntario de BIEnes de JuAn Martínez}

Este inventario sería el resultado de un proceso de actuación particular, en cuyo desarrollo se gestarían diversos documentos, de distinto tipo y otorgados en diferentes momentos, por lo que enriquecería su estudio el poder analizar su génesis, pero en esta ocasión, y dado que su búsqueda ha resultado infructuosa, no va a ser posible.

Juan Martínez, escribano público de Jerez de la Frontera, hizo testamento ante Juan Román, escribano público y del cabildo de dicha ciudad, suponemos que en torno a 1450, no podemos concretar dicha fecha dado que no se especifica en el documento ${ }^{16}$, ni tampoco hemos podido confirmarla tras la consulta de otras fuentes, en concreto los Protocolos Notariales de Jerez de la Frontera, por no conservarse ni el testamento de Juan Martínez ni el de su mujer. Según los datos aportados en el inventario, el escribano constituyó por herederos a Bartolomé Sánchez de Argumedo, Gonzalo García Candelero y Antón Martínez de Alcázar, vecinos de Jerez. Éste último, Antón Martínez, renunciaría a sus derechos de herencia ante escribano público, en favor de los otros dos herederos:

el dicho Antón Martínez renunció e traspasó en los dichos Gonçalo García e Bartolomé Sánchez, el derecho e acçión que a la herençia e bienes del dicho Juan Martínez tenía e podía aver ${ }^{17}$.

13. Recopilación de las ordenanzas... iii [Tarifas de los escribanos], 1484? ff. 72v-76r, p. 114.

14. Recopilación de las ordenanzas...11 [Tabla de derechos de los escribanos] -1490, julio, 13. Córdoba. Confirmación de los Reyes Católicos. ff. 109r-112r. Apéndice V, ord. XXXIV, p. 119.

15. Suponiendo que en su primera emisión en papel tuviera tres hojas escritas, por ambas caras, el mismo número que las que tiene el pergamino. La práctica usual apunta a que su posterior plasmación en pergamino, solía ser solicitada por los interesados, revistiéndole de un carácter más solemne y garantizando su conservación/perpetuidad.

16. El espacio reservado a tal fin aparece en blanco. Aventuramos este año, como apuntamos más adelante, en la nota 51 , a tenor de las noticias documentadas referidas a su persona.

17. Inventario, f. $1 \mathrm{r}$. 
Las disposiciones de Juan Martínez fueron también confirmadas por su mujer, Catalina Sánchez:

lo qual todo la dicha Catalina Sánchez, muger del dicho Juan Martínez, confirmó e aprovó e mandó que fuese asy tenido e guardado e conplido, e pasase por sus consentymientos e testamento. E otorgó ante escrivanos públicos desta çibdad de Xerez $^{18}$.

Con posterioridad sus herederos, Bartolomé Sánchez y Gonzalo García, queriendo respetar la voluntad de los testadores, queriendo conformarse con la voluntad de los dichos Juan Martínez e Catalina Sánchez ${ }^{19}$, para así cumplir sus últimas voluntades: E despues de su fynamiento del e della ... fuese fecho de todos ellos [sus bienes] ynventario público, e fuese puesto junto con el dicho su testamento ${ }^{20}$, plantearon su petición de que fuese realizado dicho inventario público, de todos los bienes raices que heredaron, así como de todos aquellos otros que, tras la muerte de Juan Martínez y Catalina Sánchez, compraron con lo que ellos dejaron para este fin $^{21}$. Con esta disposición el escribano jerezano perseguía que tras su muerte:

Fuesen conosçidos los dichos bienes, para que de las rentas e frutos e alogueros dellos, se pagasen e cumpliesen las capellanías e aniversarios que el dicho Juan Martínez mandó que fuesen dichos por su ánima e de la dicha Catalina Sánchez, su muger, por los frayles en los monesterios de Sant Françisco e de Santo Domingo, en la Yglesia de Sant Dionis desta çibdad, de cada un año perpetuamente. Lo qual todo la dicha Catalina Sánchez, muger del dicho Juan Martinez, confirmó e aprovó $^{22}$.

En Jerez, un miércoles, veinticuatro de enero de 1459 a ora de bísperas, cerca de la tienda de escribanía de Gonzalo Román ${ }^{23}$, en la plaza de San Dionisio, en presencia del alcalde ordinario Diego Romi de Carmona, el mozo, y obviamente ante el escribano mencionado, Gonzalo Román, y los testigos presentes al acto, se personaron los ya mencionados herederos para realizar su petición, cumpliendo

18. Inventario, f. 1v.

19. Inventario, f. 1v.

20. Inventario, f. $1 \mathrm{r}$.

21. Dicha circunstancia se indica en el inventario mediante una nota, en el espacio marginal, antes del asiento del bien en cuestión, haciendo constar "nuevo".

22. Inventario, fol. 1v. Esta disposición es una muestra de su religiosidad. Sobre el particular puede consultarse el estudio de J. ABELLÁN PÉREZ Y Ma GARCÍA GUZMÁN. La religiosidad de los jerezanos según sus testamentos (siglo XV), Cádiz, 1997.

23. Hijo de Juan Román, el escribano público ante quien testó Juan Martínez. Se observa la tradicional asociación castellana de la escribanía del número y la del concejo en un mismo individuo Así como la permanencia del cargo en la misma familia. J. ABELLÁN PÉREZ. en El concejo de Jerez de la Frontera en la primera mitad del siglo XV: composición, sistemas de elección y funcionamiento del cabildo, Jerez de la Frontera, 1990, p. 129, apunta que este fenómeno se empieza a constatar en Jerez desde "1436, año en que Juan Román, con consentimiento real, las unió a su persona hasta su fallecimiento". 
así el deseo de Juan Martínez. Comprometiéndose a dar información veraz al respecto: no harían ninguna encubierta, nin fraude, nin engaño ${ }^{24}$.

Años después, por motivos que desconocemos, sería presentado en la audiencia de Granada, formando parte de algún proceso judicial ${ }^{25}$.

El inventario se limita a una simple relación de bienes inmuebles, agrarios y urbanos, sin valorar ${ }^{26}$, no haciendo alusión a sus bienes muebles ${ }^{27}$.

A continuación pasamos a referir dichos bienes, indicando, en su caso, la extensión, ubicación, o alusión a sus linderos.

Tabla 1: Bienes

\begin{tabular}{|l|l|l|l|}
\hline BIEN & Extensión & Ubicación & Linderos \\
\hline 1 pedazo de tierra & 70 aranzadas & Bogas $^{28}$ & $\begin{array}{l}\text {-Tierra y palmar del Rey } \\
\text {-Tierra de Alfonso Díaz, jurado }\end{array}$ \\
\hline 1 pedazo de olivar & - & $\begin{array}{l}\text { Cerca de las Arboledas } \\
\text { del Fontanal }\end{array}$ & $\begin{array}{l}\text {-Olivar de García Márquez de Me- } \\
\text { dina } \\
\text {-Viña y arboleda de Mari Díaz } \\
\text {-Estacada del prior Antón Rodrí- } \\
\text { guez }\end{array}$ \\
\hline 1 pedazo de olivar & - & Cerca de La Torresilla & $\begin{array}{l}\text {-Olivar de los frailes de San Fran- } \\
\text { cisco } \\
\text {-Olivar de Alfonso Ruiz de Vejer y } \\
\text { su cuñado Fernando }\end{array}$ \\
\hline Casas & - & $\begin{array}{l}\text { C/ del Algarbe } \\
\text { (Colación de San Dio- } \\
\text { nis })^{29}\end{array}$ & $\begin{array}{l}\text {-Casa de los hijos de Gonzalo Gon- } \\
\text { zález de Andrada } \\
\text {-Casas de Alfonso Rodríguez de } \\
\text { Vejer. }\end{array}$ \\
\hline
\end{tabular}

24. Inventario, f. .2r.

25. Entre la fecha de la petición planteada por los herederos "en la noble çibdad de Xerez de la Frontera ... del mes de enero ... de mill e quatroçientos e çinquenta e nueve años", y la registrada al final del documento, "en Granada a quinze dias del mes de julio de mill e quinientos e çinquenta años", transcurre casi un siglo, noventa y un años en concreto. Ello denota la existencia de alguna causa pendiente, de un pleito, que lleva a sus interesados a recurrir a la Audiencia de Granada para su resolución.

26. Dato que en caso de incluirse sería de gran importancia para hacer una estimación precisa del nivel económico de sus propietarios, tal y como lo deduce, a tenor de este mismo tipo de fuente documental, aunque eso sí de época distinta, J. AGUADO DE LOS REYES. Riqueza y sociedad en la Sevilla del siglo XVII. Universidad de Sevilla, 1994, pp. 26-27. El autor utiliza, entre otra, este tipo de documentación para realizar su estudio. Incidiendo en los tipos de inventarios, tipo de bienes que incluyen, muebles o inmuebles, o ambos y su valoración, en el caso de incluirse. Concluyendo la categoría social y el nivel de fortuna de sus protagonistas.

27. De contemplarse la relación de los mismos enriquecería el inventario, máxime tratándose de bienes de un notario.

28. En la obra de B. GUTIÉRREZ. Historia del estado presente y antiguo, de la mui noble y mui leal ciudad de Xerez de la Frontera, Xerez, 1886, p. 23, se referencia un término similar a la "dehesa de Boyas" situándola: "a las tres leguas y media de esta ciudad, tiene legua y cuarto de largo, y una de ancho, linda con Guadalethe y tiene la fuente de la barca”. Desconocemos si puede referirse a este otro lugar, o únicamente hay parecido en sus nomenclaturas, por lo que dejamos abierta la posibilidad.

29. Morada de Juan Martínez y su mujer. 


\begin{tabular}{|c|c|c|c|}
\hline 1 tienda & - & $\begin{array}{l}\text { Plaza de San Dionis (Cer- } \\
\text { ca de la Yglesia) }\end{array}$ & $\begin{array}{l}\text {-Casa tienda del arcediano de Me- } \\
\text { dina } \\
\text {-Tienda de escribanía de Juan Ro- } \\
\text { mán }^{30} \\
\text {-Alcaicería de Jerez. }\end{array}$ \\
\hline Casas & - & $\begin{array}{l}\text { En la colación de San } \\
\text { Dionis }^{31}\end{array}$ & $\begin{array}{l}\text {-Casas de Juan Fernández el viejo, } \\
\text { carpintero. }\end{array}$ \\
\hline $\begin{array}{l}250 \text { mrs. anuales } \\
\text { de: Olivar, esta- } \\
\text { cada, viña, caña- } \\
\text { veral, arboleda y } \\
\text { tierra }^{32}\end{array}$ & - & $\begin{array}{l}\text { Fontanal, junto a la fuen- } \\
\text { te de los alunados }\end{array}$ & - \\
\hline $\begin{array}{l}\text { Dos pares de ca- } \\
\text { sas }\end{array}$ & - & Judería $^{33}$ & $\begin{array}{l}\text {-Casas de Alfonso García, prego- } \\
\text { nero } \\
\text {-Casas de Santo Tortos }\end{array}$ \\
\hline Casas & - & Colación de San Dionis ${ }^{34}$ & $\begin{array}{l}\text {-Casas tiendas de Alfonso García, } \\
\text { pregonero } \\
\text {-Casas de herederos de Diego Sán- } \\
\text { chez, çilurgano (sic) }\end{array}$ \\
\hline $\begin{array}{l}\text { Pedazo de olivar } \\
\text { estacada }^{35}\end{array}$ & - & $\begin{array}{l}\text { Mata del olivar, en la se- } \\
\text { rrana }\end{array}$ & $\begin{array}{l}\text {-Olivar de Alfonso Fernández, es- } \\
\text { cribano } \\
\text {-Olivar de Alfonso García, albañil } \\
\text {-Olivar de Juana García y Leonor } \\
\text { García }^{36}\end{array}$ \\
\hline Casa tienda ${ }^{37}$ & - & Colación de San Dionis & $\begin{array}{l}\text {-Casas de herederos de Diego Sán- } \\
\text { chez, çilurgano } \\
\text {-Tienda de Alfonso García, prego- } \\
\text { nero } \\
\text {-Casa tienda de los compradores. }\end{array}$ \\
\hline 2 casas tiendas & - & $\begin{array}{l}\text { Plazuela de la Yerua (en } \\
\text { Colación de San Dionis) }\end{array}$ & $\begin{array}{l}\text {-Casas de Juan López, barbero } \\
\text {-Casas de Gonzalo García de Le- } \\
\text { desma }^{38} \\
\text {-Casas de Antón García, sillero } \\
\text {-Casas de Inés Miraval } \\
\text {-Casas de Gonzalo García de Le- } \\
\text { desma } \\
\text {-la Plazuela }{ }^{40}\end{array}$ \\
\hline
\end{tabular}

30. "Escribano público y del cabildo que Dios aya". Inventario, f. 2r.

31. Morada de su hermana Isabel Martínez.

32. Por el alquiler perpetuo, de todo ello, a Antón Gil de Algeciras y su mujer, que pagaban dicha cantidad de tributo y censo cada año.

33. Eran de Pedro Sánchez de Algeciras y de su mujer.

34. Que fue de Beatriz Alfonso, mujer de Juan González de Marchena.

35. Aparece como propiedad de Juan Martínez y de su mujer. No especifica el número de las aranzadas.

36. Apodadas las naranjas.

37. Que fue de Alfonso García, pregonero.

38. Lindes de la primera casa tienda.

39. Mujer de Fernando de Villavicenci.

40. Lindes de la segunda casa tienda. 


\begin{tabular}{|l|l|l|l|}
\hline 1 caballería $^{41}$ & - & $\begin{array}{l}\text { Bogas (en la parte del } \\
\text { Exido y del agua de año- } \\
\text { ruela) }\end{array}$ & $\begin{array}{l}\text {-Tierra de herederos de Juan Gar- } \\
\text { cía de Natera } \\
\text {-Tierra de las Naranjas } \\
\text {-Tierras de Doña Francisca y del } \\
\text { camino. }\end{array}$ \\
\hline 1 corralejo $^{42}$ & - & - & $\begin{array}{l}\text {-Casa tienda de Gonzalo García y } \\
\text { de Bartolomé Sánchez } \\
\text {-Casas tyenda de Diego Sánchez } \\
\text { de Baños. }\end{array}$ \\
\hline $\begin{array}{l}1 \text { pedazo de tie- } \\
\text { rra }^{44}\end{array}$ & $\begin{array}{l}\text { En Bogas (En la parte del } \\
\text { Exido y agua del añorie- } \\
\text { ta) }\end{array}$ & $\begin{array}{l}\text {-Tierra de herederos de Juan Gar- } \\
\text { cía de Natera. } \\
\text {-Tierras de Juan Martínez, escriba- } \\
\text { no, y de su mujer. } \\
\text {-Tierras de las Naranjas. } \\
\text {-Tierra de Doña Francisca y del } \\
\text { camino. }\end{array}$ \\
\hline $\begin{array}{l}1 \text { casa, tienda y } \\
\text { soberado }\end{array}$ & $\begin{array}{l}\text { y } \\
100 \text { mrs. }^{46}\end{array}$ & $\begin{array}{l}\text { En colación de San Dio- } \\
\text { nis }\end{array}$ & $\begin{array}{l}\text {-Casas tiendas de los compradores } \\
\text {-Casa de Diego Fernández de Mi- } \\
\text { lán } \\
\text {-de la calle. }\end{array}$ \\
\hline
\end{tabular}

Los beneficiados se comprometen a no vender, empeñar, ni cambiar los bienes declarados, ni ellos, ni sus herederos, ni descendientes. Solamente usarían de ellos, de sus frutos y rentas, según estipuló Juan Martínez en su testamento, y luego confirmó su mujer.

\section{JuAn MARTÍNEZ}

Poco sabemos respecto a la persona de este escribano jerezano. La consulta de las Actas Capitulares, conservadas en el Archivo Municipal de Jerez de la Frontera, no son prolijas al respecto. Únicamente desvelan como Juan Martínez ya en 1410 ejercía su cargo de escribano público, y a partir de este año hemos encontra-

41. Especifica en concreto "cavallería de tierra". No entrando en este momento en dilucidar su sentido.

42. Salía de unas casas propiedad de Elvira Sánchez, hija de Diego Sánchez, "çilurgano" y propietario anterior de las mismas.

43. Que había comprado a Alfonso García, pregonero.

44. En que había dos caballerías.

45. Que se compró de Diego de Tineo y de Beatriz García, su mujer.

46. Que recibían perpetuamente cada año, de tributo y censo, por parte de Pedro Martínez Camacho, vecino en el arrabal de Santiago de la ciudad. Los cuales debía pagar el día de San Miguel de Septiembre, por las dichas dos aranzadas de tierra en la Serrana. 
do referencia a su persona en $1424^{47}, 1426,1427,1431,1433,1435,1437^{48}, 1438$, 1443 y por último en 1450, con ocasión de la concesión, por parte de Juan II, de una escribanía pública del número de la ciudad a Juan Bernal, menor de edad. Dado que para ejercer debía tener la mayoría de edad "fasta que vos seays de hedad conplida de diez e ocho años" y que había llegado a noticia del monarca la habilidad de Juan Martínez, decide que éste ejerza como escribano público del número:

Yo soy ynformado que Juan Martínez de Sanlúcar, mi escrivano e notario público en la mi corte ... e vezino de la dicha çibdad, es persona abile e pertenesçiente e sufiçiente para que por vos e en vuestro lugar pueda usar el dicho ofiçio de escrivanía pública. Por ende yo por la presente pongo por escrivano público en vuestro lugar e por vos, de la dicha çibdad, al dicho Juan Martínez, al qual desde agora do decreto, e abtoridad e poderío para que durante el dicho tiempo de vuestra menor hedad e fasta que vos ayades los dichos diez e ocho años conplidos, pueda usar e use del dicho ofiçio de escrivanía pública de la dicha çibdad de Xerez, segund e en la manera que usan los otros mis escrivanos publicos de la dicha çibdad. E tengo por bien e es mi merçed e mando que todas las escripturas, de qualquier condiçión que sean, que pasaren ante el dicho Juan Martinez, durante este dicho tienpo en que fuere puesto, el día e el mes e el año, e su sygno acostumbrado goze como mi escrivano e notario público... e goze e le sean guardadas todas las onras e graçias, e merçedes, e franquezas, e libertades, e esençiomes, e previllejos, e todas las otras cosas e cada una de ellas que fueron e son e deven ser guardadas, a cada uno de los otros mis escrivanos públicos del número de la dicha çibdad. El qual dicho poderío e abtoridad do al dicho Juan Martinez ... fasta el dicho tienpo de la dicha vuestra hedad de diez e ocho años conplidos e no más ... ${ }^{49}$.

Con posterioridad las Actas no refieren ninguna noticia alusiva a él, a su mujer, ni tampoco a ninguno de los beneficiados por su testamento. Por su parte los Protocolos Notariales, conservados en dicho Archivo, aluden a su persona y cargo en

47. En las Actas y en un escrito de González de Heredia, vecino de Jerez, escribano del Rey y su notario público. Fechado en Jerez el 30 de diciembre de 1424. Este escribano reconoce que sólo los seis escribanos públicos del número de Jerez tenían derecho a realizar, sólo ellos y no los reales, testamentos y escrituras, según lo ordenó el Rey Don Juan. Citando a: Diego Arias, Alfonso García, Juan Román, Diego Gómez, Juan Martínez y Nuño Díaz. La alusión a este escrito la hemos encontrado en un pleito entre escribanos conservado en el ARCHGR, Caja 205, legajo 5352-8. Pleito estudiado y presentado para su publicación en el próximo número de la Revista: Estudios sobre Patrimonio, Cultura y Ciencias medievales.

48. En la obra citada de J. ABELLÁN PÉREZ. El concejo jerezano... p. 119, alude al nombre de Juan Martínez en 1437, con motivo de la elección de cargos concejiles pendientes.

49. 1450-X-4. Olmedo, publicado por J. ABELLÁN PÉREZ. El concejo de Jerez ..., op.cit. p. 222. Este nombramiento constituye un importante dato a tener en cuenta a la hora del estudio del notariado andaluz. Aventuramos que por renuncia de su poseedor y para garantizar el cargo en Juan Bernal, éste sería nombrado a pesar de su minoría de edad, sin ello suponer una traba. Subsanando la situación con el nombramiento condicional de Juan Martínez. 
los protocolos de 1414 y 1448, refiriendo a su tienda de escribanía en la plaza de San Dionisio ${ }^{50}$, por lo que podemos suponer su fallecimiento entre 1450 y $1459^{51}$.

En una Real Provisión de Juan I, inserta su copia en las Actas Capitulares de Jerez de la Frontera ${ }^{52}$, queda documentado, como es bien sabido, que el número de escribanías públicas para este periodo debía ser el de seis ${ }^{53}$. De igual modo la consulta de las Actas nos ha llevado a constatar como práctica usual, durante casi toda la primera mitad del siglo $\mathrm{XV}$, y a pesar de la prohibición al respecto, el que los diversos oficiales, entre ellos los escribanos, ejerciesen dos oficios. En este sentido Juan Martínez, siendo escribano público, desempeñó simultáneamente otras funciones, entre ellas:

Procurador en 1410, 1426 y 1427. En este último año queda registrado que por tal cometido le abonaron a él y a Ferrand González, notario, 150 maravedís, por la costa de ir a Medina Sidonia, a actuar como tal ${ }^{54}$.

En los años 1431, 1433, 1435, 1437 y 1438 ejerció como alcalde ordinario. En concreto en 1438 fue designado alcalde ordinario en lugar de Rodríguez de Cuenca ${ }^{55}$.

Durante el año 1436 ejerció el oficio de juez ${ }^{56}$.

Respecto a las tres personas designadas como beneficiarios de su testamento, son prácticamente nulas las referencias, encontrando documentada la figura de Bartolomé Sánchez en el Acta de 1433, ejerciendo como escribano de la mesta, alfayate ${ }^{57}$. Sobre Gonzalo García sólo decir que este nombre aparece en la validatio de tres traslados de cartas de Juan II, insertos en las Actas Capitulares de 1433 y $1435^{58}$. Sobre Antón Martínez aludir a que hemos encontrado citado este mismo nombre en 1410 y en 1433, figurando como jurado en la colación de San Miguel ${ }^{59}$.

50. AHMJ, PN 1414, ff. 57r.-v, 131v-132r. y PN 1448, en el que aparecen como escribanos, además de Juan Martínez, Antón Franco, Diego García de Salas y Antón Martínez.

51. Dado que después del documento real de Juan II, del año 1450, aludido en la nota 49, no hemos encontrado ninguna otra noticia, y en 1459 es cuando aparece fechado este inventario.

52. AHMJ, AC 1505, f. 621r-v, citado en el estudio de $M^{a} D$. ROJAS VACA. "Notariado público y Documento Notarial en Jerez ...”, p. 294. "Fasta que los dichos escrivanos sean tornados en número de seys". Documento fechado en Ávila, el día 27 de octubre de 1419.

53. Número al que alude también el escrito de González de Heredia, de 1424, citado en la nota 47.

54. AHMJ, AC 1427, f. 11v.

55. AHMJ, AC 1438, f. 108v.

56. Noticia recogida por J. ABELLÁN. el concejo de Jerez ..., op. cit., p. 130.

57. AHMJ, Acta Capitular de 1433, f. 20r.. Este dato está recogido en la obra citada de J. ABELLÁN PÉREZ. El concejo de Jerez..., p. 103, al aludir a que el miércoles, 28 de enero de ese año, se dieron a conocer en el cabildo los oficios correspondientes a la colación de San Salvador.

58. AHMJ, AC 1433, f. 47v. AC 1435, f. 119r. y AC 1435, f. 61r. Editado por J. ABELLÁN PÉREZ. Diplomatario del Reino de Granada. Documentos de Juan II de Castilla (1407-1454) del Archivo Municipal de Jerez de la Frontera, Universidad de Granada, 2011, pp. 32-37.

59. En AHMJ, Acta Capitular de 1433, f. 19v. El sábado, día 24 de enero de 1433, con ocasión de confirmar los maravedís asignados al alcayde Gonzalo Fernández, por “tenencia del castillo del Tempul". No podemos asegurar que se trate de la misma persona, pero dada la coincidencia del nombre, y además por la fecha, cabe la posibilidad de que este beneficiado fuese dicho jurado. Como tal aparece aludido en la obra de J. ABELLÁN PÉREZ. El Concejo de Jerez ..., Jerez de la Frontera, 1990, p. 59. 


\section{ANÁLISIS DOCUMENTAL}

El documento consta de cuatro hojas, la última en blanco, escritas por ambas caras, escritura opistógrafa, a línea tendida por el lado más estrecho, en vertical, sin pautado, y realizado en pergamino de 280 x $200 \mathrm{~mm}$., conformando un cuadernillo cuyas hojas aparecen unidas por su margen izquierdo con hilo bramante, sin foliación. Guarda márgenes superior, inferior, derecho e izquierdo en todas sus hojas. Utilizando el izquierdo para la incorporación de alguna nota esporádica. Su estado de conservación es bueno, únicamente está roto por el extremo del margen superior, sin llegar a afectar a la parte escrita.

La tinta utilizada es de color negro que, por su composición, ha adquirido con el tiempo la típica tonalidad ocre. Mostrando un tono más claro uno de los párrafos del vuelto de la segunda hoja, así como las firmas de los testigos que lo validan y la nota final, añadida años después en Granada, todo ello en el vuelto de la tercera hoja, al final del documento, según puede comprobarse en la figura $n^{\circ} 2$.

Todas las hojas, menos la última, acaban con la inclusión de la línea de cierre, el cursor final, delimitando el pie de la mancha de escritura, que incluye, en su parte central, el nombre y rúbrica de Gonzalo Román, escribano, con la finalidad de evitar interpolaciones en su contenido. No apareciendo en la cabecera en ninguna de ellas.

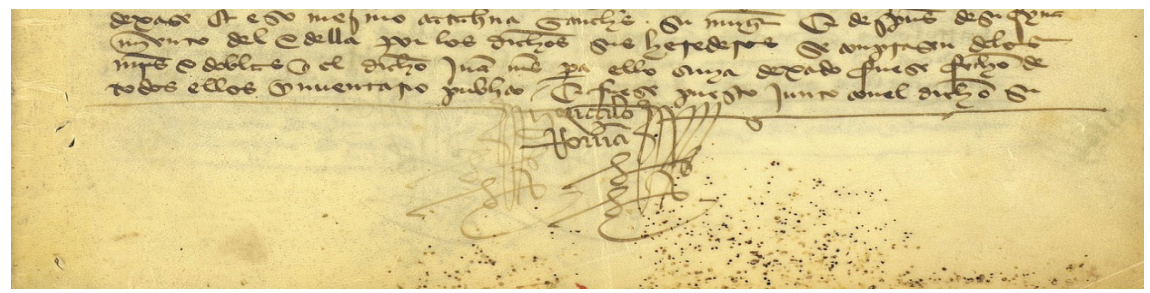

Figura $n^{0} 1$

Está realizado en la típica escritura gótica cursiva del momento, la escritura cortesana. Escritura minúscula en cuyo trazado abundan las ligaduras, propias del ductus cursivo, y también las abreviaturas, tanto del tipo de suspensión como de contracción, aunque predominen estas últimas ${ }^{60}$.

60. La escritura cortesana constituye un tipo gráfico de demostrada entidad en este periodo de la historia de la escritura.. Al respecto de la escritura gótica son de obligada consulta, entre otros, los magníficos estudios de C. DEL CAMINO MARTÍNEZ. "La escritura de los escribanos públicos de Sevilla (1253-1300)", HID, 15, (1988), pp. 145-165. "La escritura de la documentación notarial en la época colombina”, en Tra Siviglia e Genova: Notaio, Documento e Commercio nell'Età Colombiana, (Milán, 1994), pp. 485-501. "La escritura de la documentación notarial en el siglo XIV”, Cuadernos del Archivo Central de Ceuta, 15, (2006), pp. 29-56. Y de la misma autora, "Notarios y escritura ¿Un signo externo de distinción?”, en A. MORENO TRUJILLO, J.Mª, OSORIO PÉREZ (Eds). El Notariado andaluz. Institución, práctica notarial y archivos, (Granada, 2011), pp. 109-232. O los estudios de M J., SANZ FUENTES. "Paleografía en la Baja Edad Media castellana", Anuario de Estudios Medie- 
Entre los elementos figurados debemos mencionar la rúbrica y signo de Gonzalo Román, escribano público de Jerez, así como la rúbrica del alcalde, Diego Romi, y la de tres de los cuatro testigos mencionados en el documento, todos ellos escribanos: Ferrando de Orvaneja, Antón Franco y Diego Sánchez. Faltando la de Alfonso Martínez.

Constatamos en su factura la intervención de diversas manos. Entre ellas obviamente la de su autor material, que queda en el anonimato, la de Gonzalo Román, rogatario que con su signo y rúbrica valida la acción documental, y también, dentro de la validatio, la rúbrica de los citados testigos, el alcalde y los escribanos. Y por último una mano distinta y en una escritura posterior, procesal, incluye la referencia de cuándo y quien presentó el documento en Granada.

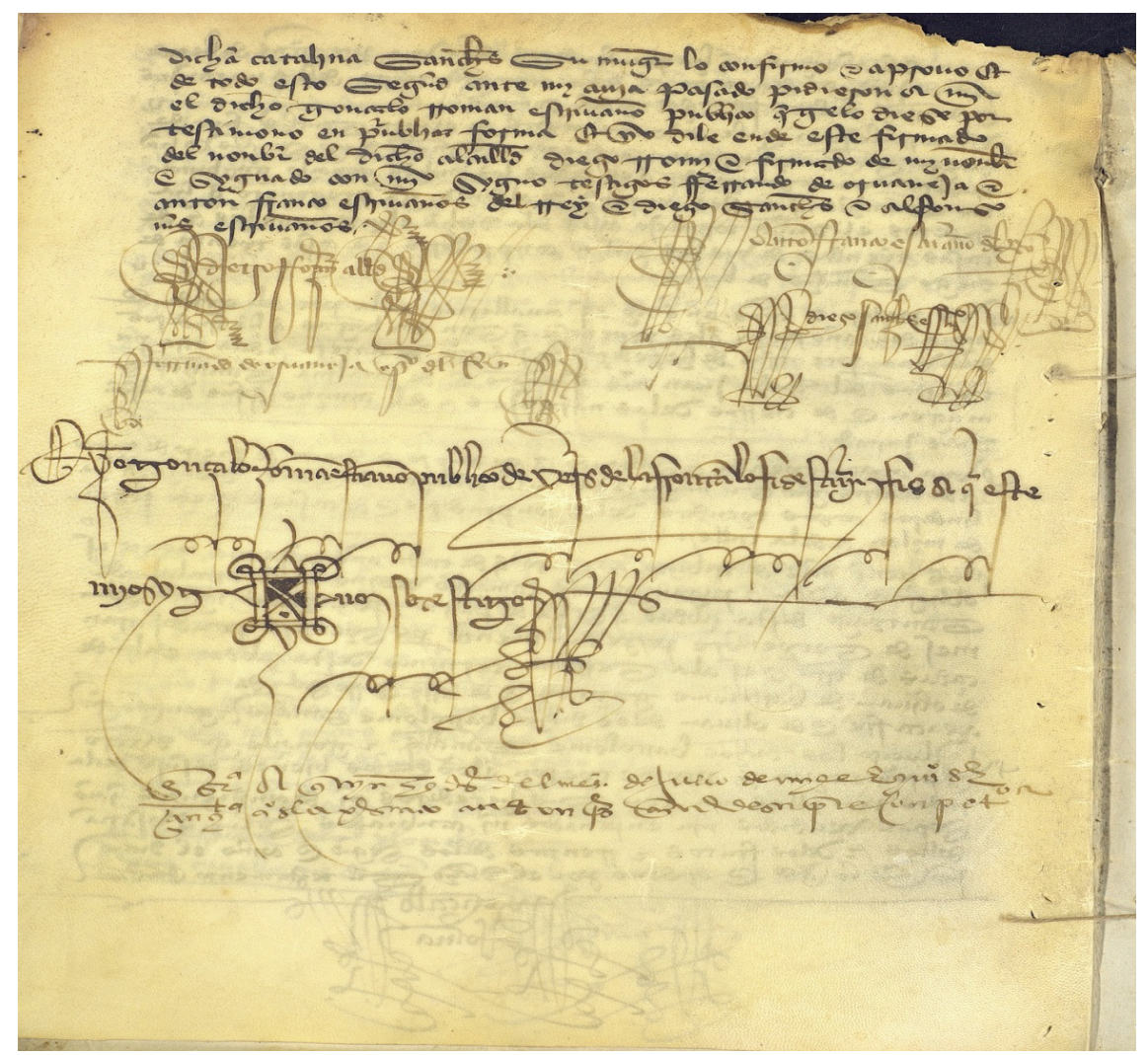

Figura $\mathrm{n}^{\mathrm{o}} 2$

vales, 21, (1991), pp. 520-545. Y de la misma autora: "La escritura gótica documental en la Corona de Castilla”, en M. CALLEJA PUERTA, M J. SANZ FUENTES. (coords.). Paleografia II: las escrituras góticas desde 1250 hasta la imprenta. V Jornadas de la Sociedad Española de Ciencias y Técnicas Historiográficas, Oviedo, 18 y 19 de junio de 2007, (Oviedo, 2010), pp. 107-126. 
El cuaderno está redactado, de manera objetiva, en el castellano de la época, resultando en su conjunto un texto cuidado, aunque esporádicamente detectemos la utilización de arcaísmos: $s c ̧$, nesçesario, paresçieron, $p t$, escripto. Indecisiones en alternancias formales y en vacilaciones de timbre, por ejemplo Y-I, Tyerras, tierras.

Su estructura diplomática resulta simple, no presentando una gran dificultad. Incluyendo a lo largo de su discurso pistas sobre el proceso de su génesis:

El documento inicia su tenor con la inclusión de la Data, tópica, especificando no sólo la ciudad, Xerez, donde el documento se otorgó, sino además el lugar, cerca de la tyenda de la escrivania pública ... que es en la plaça de Sant Dionis ... ${ }^{61}$, y crónica, indicando día de la semana, del mes, mes, por el sistema directo, y año del otorgamiento, éste expresado según el sistema de la era cristiana con su principio calculado de acuerdo con el estilo de la Natividad: miércoles veynte e quatro días del mes de enero, año del nasçimiento del nuestro Saluador Ihesu Christo..., con alusión además a la hora, a ora de bísperas.

Tras ello pasa a incluir la Fórmula de aseveración de presencia notariotestifical:

estando ende Diego Romi de Carmona el moço, alcalde ordinario ... En presencia de mi, Gonçalo Román, escribano público ... e de los otros escribanos e testigos deiuso escriptos, que a esto fueron presentes en testimonio ${ }^{62}$.

A continuación se detallan los nombres de los beneficiarios del testamento de Juan Martínez, y autores de la acción documental de este Inventario, del asunto documentado, la Fórmula de comparecencia: Bartolomé Sánchez de Argumedo y Gonzalo García, quienes exponen como Juan Martínez los designó como herederos universales, junto a Antón Martínez del Alcázar, quien, tras el fallecimiento del testador, renunció a su derecho en beneficio de ellos. Incluyendo además el nombre del Alcalde que debía resolver su petición, Diego Romi.

Más adelante se incluye la Exposición de los motivos que llevan a la realización del documento:

61. Las Actas Capitulares aluden a esta tienda de escribanía en 1436, indicando su mal estado de conservación en dicho año, AHMJ, AC 1436, f. 130v:

Porque la tyenda de la escribanía pública de Xerez que tyene en la plaça de Sant Dionis, junta con el / alcaçería, que Xerez syenpre dio a su escrivanno del cabildo, está para se caer, de que podrá venir / peligro. E por esto e porque la dicha tyenda es pequeña, rogaron e mandaron a Nuño Díaz, escrivanno / público desta çibdad que faga derocar lo que de la dicha tyenda se quiere caer e se tyene / con cientos de maderos. E que faga alargar e alçar la dicha tienda e soberadalla, en manera / que sea fecha commo a onra de Xerez cunpla. E porque al presente e para en este año tyene / dineros para obrar la dicha tyenda, el dicho Nuño Díaz gaste e desprenda los maravedís que costara / e faser, en lo que mostrare e gasto en la dicha obra con su juramento. gelos libraran en los maravedis / de las rentas e propios desta çibdad, del primero terçio del año primero que viene de mill e quatroçientos $e$ treynta e seys años. $/$.

62. Inventario, f.1r. 
...Por ende ellos queriendo conformarse con la voluntad de los dichos Juan Martínez e Catalina Sánchez, su muger, e compliendo los dichos sus testamentos, querían fazer el dicho ynventario público....

Expuesto el desarrollo de las motivaciones pasan a plantear su petición de hacer público dicho inventario, pidiendo para ello licencia al alcalde, Diego Romi.

Tras dicha exposición se intenta hacer efectiva la Disposición, previa petición, a la autoridad pertinente:

E que sy nesçesario era en ello entrevenir liçençia del dicho alcalde, que ge la pedian porque ellos lo pudiesen fazer [el inventatrio]... E luego el dicho alcalde Diego Romi, visto el dicho pedimiento dixo que en quanto podía, e de derecho devía, les dava e dio liçençia para fazer el dicho ynventario ... ${ }^{63}$.

Formando parte de las Claúsulas de promesa u obligación, se refleja como los herederos dejaban clara su intención de actuar correctamente, comprometiéndose a declarar, sin engaño, todos los bienes que dejaron a su muerte, así como los que después fueron comprados por ellos, cumpliendo la voluntad de dichos testadores, para lo que:

juraron por el nombre de Dios e de Santa María, e por las palabras de los santos evangelios onde quier que son, e sobre la señal de la cruz en que pusieron sus manos derechas.

\section{bienes.}

El siguiente punto incluye el detalle de todos los bienes ${ }^{64}$, el Inventario de

El Documento concluye con la Validación, aludiendo a los testigos que estuvieron presentes en esta declaración de bienes, e inclusión de sus rúbricas, a excepción de la de uno de ellos, testificación y suscripciones, autógrafas, corroborando el documento además la inclusión de la rúbrica y signo de su auctor, rogatario, el escribano público Gonzalo Román, hijo del también escribano público y del cabildo, Juan Román ${ }^{65}$, quien consiguió como ocurría en el caso de otros oficios, como regidores o jurados, el otorgamiento de cartas expectativas que aseguraban

63. Inventario, f.1r.

64. Cada uno de los párrafos en que se detallan dichos bienes, van precedidos por un calderón cursivo.

65. B. GUTIÉRREZ. en su obra ya citada Historia del estado ..., al aludir en la página 59, a los seis oficios primeros que se crearon en 1320, indica la lista de escribanos, y entre ellos menciona a Gonzalo Román, Juan Román, su hijo, para luego pasar a Francisco Román de Truxillo, Juan Román de Truxillo, continuando el listado hasta el año 1756. La lectura tanto de este inventario como de las Actas conservadas de Jerez de la Frontera, aluden a Gonzalo Román como hijo de Juan Román, no al contrario, tal y como consta en la citada obra. En las Actas encontramos alusión, tras Gonzalo Román, a Francisco Román de Trujillo, a partir de 1513, y en 1550 ya aparece mencionado Juan Román de Trujillo. No pretendemos dar a entender que este ilustre historiador errase en dicha enumeración, simplemente nos limitamos a exponer los datos que hemos entresacado tras la consulta de las fuentes, y lectura de otros estudios donde también aparece incluido este detalle, para que en algún otro estudio orientado hacia esta línea pueda ser tenido en cuenta. 
la continuidad del cargo en la familia. Obteniendo de Juan II, en 1445, la facultad para renunciar, cuando quisiera, en su hijo Gonzalo Román ${ }^{66}$.

\section{CONClusión}

Nuestro objetivo primordial al realizar este estudio ha sido dar a conocer el documento, hasta ahora inédito, relativo a los bienes de un escribano público de Jerez en la primera mitad del siglo XV.

A pesar de que el inventario refiere exclusivamente la relación de bienes inmuebles, obviando los muebles, cuya inclusión dotaría al documento de una mayor relevancia, creemos que puede resultar interesante dado su carácter genuino ${ }^{67}$.

Somos conscientes de aspectos que quedan sin aclarar, bien por falta de concreción del propio documento: Omisión de fechas exactas, no inclusión de otros bienes de Juan Martínez ${ }^{68}$. O de otros en los que, aún incluidos en el documento, no hemos profundizado: Nombramiento de Juan Martínez como escribano público del número, cubriendo una minoría de edad $^{69}$. El por qué del largo lapsus de tiempo entre la realización del inventario y su presentación en la Chancillería, etc.

Dar a conocer el Inventario deja la puerta abierta para la realización de futuros estudios, en los que quizás se puedan despejar las dudas planteadas en esta ocasión.

66. 1445-VII-4. Mayorga. ARCHGR. ACJ, 1450, f.60v-61r. Publicado por J. ABELLÁN PÉREZ. El concejo de Jerez..., op. cit. Doc. $\mathrm{n}^{\mathrm{o}} 27$, p. 174. M ${ }^{\mathrm{a} D}$. ROJAS VACA en su obra ya citada, en nota número 3, sobre "las escribanías del cabildo municipal de Jerez...", p 288, alude a la práctica que lleva a que el oficio de escribano de cabildo recaiga en una familia. Apunta además al hecho de que el oficio de escribano mayor del cabildo "de ser de nombramiento concejil, pasa a ser de nombramiento real, de ser elegido entre los vecinos de una collación, por turnos anuales, a recaer en una familia, de anual a vitalicio".

67. No tenemos constancia de estudios sobre inventarios de escribanos jerezanos en esta época.

68. Lo que lleva a deducir la finalidad perseguida: Garantizar en perpetuidad el pago de las capellanías y aniversarios, incluidos en las mandas testamentarias de Juan Martínez.

69. Al respecto hay que recordar el dato apuntado en la nota 47: En 1424 Juan Martínez aparece citado como uno de los seis escribanos del número de Jerez. 


\section{ApÉNDICE DOCUMENTAL}

1459, enero, 24. Jerez de la Frontera

Inventario de bienes del testamento de Juan Martínez, escribano público de la ciudad de Jerez de la Frontera, a petición de Bartolomé Sánchez de Argumedo y Gonzalo García Candelero, herederos.

A.-ARCHGR. ES.18087. 060CDMA. Colección de documentos manuscritos. Pergamino $\mathrm{n}^{\circ} 191$.

En la noble çibdad de Xerez de la Frontera, miércoles veynte e quatro / días del mes de enero, año del nasçimiento del nuestro Salvador / Ihesu Christo de mill e quatroçientos e çinquenta e nueve años, a ora de bísperas / dichas, çerca de la tyenda de la escrivania pública de mi Gonçalo Roman, / escrivano público desta çibdad de Xerez, que es en la plaça de Sant Dionis / della.

Estando ende Diego Romi de Carmona el moço, alcalde ordinario / en esta çibdad de Xerez, en lugar del honrado cavallero Tristán de Aça, corregidor e justiçia mayor desta çibdad, por el manifico señor Don Juan / Pacheco, marqués de Villena, mayordomo mayor del Rey, nuestro Señor, e su / corregidor e justiçia mayor desta çibdad de Xerez.

En presençia de mi, / Gonçalo Román, escrivano público desta çibdad de Xerez, e de los otros escrivanos / e testigos diuso escriptos que a esto fueron presentes en testimonio, / paresçieron: Bartolomé Sánchez de Argumedo e Gonçalo Garçia Candelero, / vezinos desta çibdad de Xerez, los quales, en presençia del dicho escrivano público, dixeron que por quanto Juan Martínez, escrivano público / desta çibdad, cuya ánima Dios aya, al tiempo e sazón que fizo e otorgó / su testamento e postrimera voluntad ante Juan Román, escrivano público desta çibdad de Xerez en [en blanco] días del mes de [en blanco] del año / que pasó del Señor de mill e quatroçientos e çinquenta e [en blanco] años, / entre otras cosas en el dicho testamento contenidas, constituyó por / sus herederos universales en todos sus bienes e herençia a los / dichos Bartolomé Sánchez e Gonçalo García e a Antón Martínez del Alcaçar, vesino desta çibdad. E fallesçido desta presente vida, el dicho Juan Martínes, el dicho Antón Martínez renunçió e traspasó en los dichos Gonçalo García e Bartolo-/mé Sánchez, el derecho e acçión que a la herençia e bienes del dicho / Juan Martínez tenía e podía auer, segund dixeron que pasó ante escribano público / desta çibdad. E que eso mesmo el dicho Juan Martínez por el dicho su testamento / mandó e ordenó que de los bienes rayses que al tiempo de su finamiento el / dexase. E eso mesmo Catalina Sánchez, su muger. E después de su fyna-/miento del e della por los dichos sus herederos se comprasen de los / maravedís e doblas que el dicho Juan Martínez para ello avia dexado, fuese fecho de / todos ellos ynventario público, e fuese puesto junto con el dicho $\mathrm{su}^{70} / /{ }^{1 \mathrm{r}}$. testamento, porque fuesen conosçidos los dichos bienes, para que de las / rentas e frutos e alogueros dellos, se pagasen e cumpliesen las / capellanías e aniversarios que el dicho Juan Martínez mandó que fuesen / dichos, por su ánima e de la dicha Catalina Sánchez, su muger, / por los frayles en los monasterios de Sant Françisco e de Santo Domingo, en la yglesia de Sant Dionis desta çibdad, de cada un año, / perpetuamente para siempre jamás. E eso mesmo por los clérigos / de la dicha iglesia de Sant Dionis. E los maravedís que a la fábrica de la / dicha iglesia mando que fuesen dados de cada un año perpetua-/mente, lo qual todo la dicha Catalina Sánchez, muger del dicho Juan / Martínez, confirmó e aprobó e mandó que fuese asy tenido

70. [línea de cierre: Gonçalo /Román]. 
e guarda-/do e conplido, e pasase por sus consentymientos e testamento, / e otorgó ante escrivanos públicos desta çibdad de Xerez.

Por / ende que ellos queriendo conformarse con la voluntad de los dichos / Juan Martínez e Catalina Sánches, su muger, e conpliendo los dichos / sus testamentos, querían faser el dicho ynventario público / de todos los bienes rayses que ellos por sus herençias ovieron, / e eso mesmo de todo o los otros que después de fynamiento del / dicho Juan Martynez e Catalina Sánchez, su muger, fueron <comprados>, de lo / que ellos dexaron para los comprar. E que sy nesçesario era en ello / entrevenir liçençia del dicho alcalde, que ge la pedían porque ellos / lo pudiesen faser, segund e como los dichos Juan Martínez e Catalina / Sánchez, su muger, lo mandaron e ordenaron.

E luego el dicho / alcalde Diego Romi, visto el dicho pedimiento dixo que en quanto podía / e de derecho devía, les dava e dio liçençia para faser el dicho ynven-/tario e declarar por el los dichos bienes, segund e por la / forma e manera e como los dichos Juan Martínez e Catalina Sánchez, / su muger, lo quesyeron e ordenaron por sus testamentos e / voluntad postrimera. E luego reçibió juramento de los dichos / Bartolomé Sánchez e Gonçalo Garçía. E ellos juraron por el nombre / de Dios e de Santa María, e por las palabras de los Santos / evangellos onde quier que son, e sobre la señal de la cruz en que $e^{71} / /^{1 \mathrm{v}}$. pusieron sus manos derechas, que farían el dicho ynventario e / declaraçión de bienes, bien e verdaderamente e por el no encubre-/rían ningunos ni algunos bienes rayses, asy de los que los dichos Juan / Martínez e su muger, al tiempo de su finamiento dexaron, como de los / que después de fynamiento del dicho Juan Martínez por ellos fueron comprados. / De lo qual dicho Juan Martínez para ello avía dexado e guardarían la voluntad / de los dichos testadores, e no farían ninguna encubierta nin fraude, / nin engaño.

E luego los dichos Gonçalo Garçía e Bartolomé Sánchez, / declararon e dixeron que los bienes que los dichos Juan Martínez e Catalina / Sánchez, su muger, dexaron al tiempo de su finamiento, e eso mesmo / los que después de su finamiento del dicho Juan Martínez ellos avían / conprado de lo quel auía para ello dexado, eran çiertos bienes rayses / que estavan escriptos e nombrados por çiertas escripturas públicas, / escriptas en pergamino de cuero, firmadas e signadas de escrivano / público, que luego presentaron, que fueron sacados por menudos suma-/riamente por mí el dicho escriuano público, en presençia de los dichos / Bartolomé Sánchez e Gonçalo García, que son estos bienes que se siguen: /

$<$ nuevo> (signo) Un pedaço de tierras en que ay setenta arançadas, que es a Boyas, termino / desta çibdad, que ha en linderos tierra e palmar del Rey, e tierra de Alfonso / Díaz, jurado. /

(signo) Un pedaço de olivar que es çerca de las arboledas del Fontanal, en linde / de olivar de Garçía Marquez de Medina, e de viña e arboleda de Mari Díaz, / e estacada del prior Antón Rodríguez. /

(signo) Otro pedaço de olivar que es çerca de la Torresilla, termino desta çibdad, / que ha por linderos olivar de los frayles de Sant Françisco e de olivar / de Alfonso Royz de Vejer e de Ferrando, su cuñado. /

(signo) Unas casas que son en la collaçión de Sant Dionis desta çibdad que / fueron de la morada del dicho Juan Martínez, escrivano público, e Catalina / Sánchez, su muger, que son a la calle del algarbe, que ha por linderos / casas de los fijos de Gonçalo Gonçalez de Andrada, e de casas de Alfonso / Rodríguez de Vejer. /

(signo) Una tienda que es en la plaça de Sant Dionis desta çibdat, çerca de la dicha / Yglesia que ha por linderos de la vna parte casa tyenda del arçediano de Medina, / e de

71. [línea de cierre: Gonçalo /Román]. 
tyenda de escrivanía de Juan Román, escrivano público e del cabildo, que Dios aya, e del alcaçería de Xerez ${ }^{72}$. // ${ }^{2 r}$.

(signo) Unas casas que son en la collaçión de Sant Dionis, que eran de la mo-/rada de Ysabel Martínez, hermana del dicho Juan Martínez, que son en linde de / casas de Juan Ferrández el viejo, carpintero, e de casas de [en blanco] / e de la calle. /

(signo) Los dosientos e çinquenta maravedís que han de dar Antón Gil de Algezira e su / muger, de tributo e çienso de cada año, perpetuamente, del peda-/ço de olivar e estacada e viña e cañaveral e arboleda e tierra que es / al fontanal, junto a la fuente de los alunados. /

(signo) Dos pares de casas que son juntas en la judería que era de Pedro Sánchez / de Algezira e su muger, que han linderos casas de Alfonso Garçía, / pregonero, e de casas de Santo Corcos e de las calles. /

(signo) Unas casas que son en la collaçión de Sant Dionis, que fue de Beatriz / Alfonso, muger de Juan Gonçalez de Marchena, en linde de casas tiendas / de Alfonso Garçía, pregonero, de las dos partes, e de casas de herederos de Diego Sánchez çilurgano. /

(signo) Un pedaço de olivar estacada que fue de los dichos Juan Martínez e Catalina Sán-/chez, su muger, en que puede aver [en blanco] arançadas, que es en la mata del / olivar desta çibdad a la serrana, que ha por linderos, de la una parte olivar / de Alfonso Ferrández, escribano, e de olivar de Alfonso Garçía, albañi, e de la otra parte / olivar de Juana Garçía e Leonor Garçía, las naranjas. /

(signo) Una casa tyenda que fue de Alfonso Garçía, pregonero, que es en la collaçión / de Sant Dionis, que ha por linderos de las dos partes, casas de herederos / de Diego Sánchez, çilurgano e de la otra parte tyenda del dicho Alfonso / Garçía, pregonero, e de casa tyenda de los compradores. /

(signo) Dos casas tiendas que fueron de Leonor Rodríguez, fija de Ferrand Ro-/dríguez Caçaby, muger de Pedro Garçía de Cordova, que son en la collaçión de Sant / Dionis, a la plaçuela de la Yerua, que ha linderos, la una casa tyenda / de la una parte casas de Juan Lópes, barvero, e de la otra parte, casas / de Gonçalo Garçía de Ledesma, e de la calle e la otra casa tyenda ha / linderos casas de Antón García, syllero, e de la otra parte casas de Ynés / Miraual, muger de Ferrando de Villaviçenci, e de casas de Gonçalo Garçía / de Ledesma, e de la plaçuela. /

$<$ nuevo $>$ (signo) Una cavallería de tierra que es en bogas con la parte del Exido e del ${ }^{73}$ $/ / 2 v$. agua del Añoruela, que ha por linderos de la vna parte tierras de herede-/ros de Juan Garçía de Natera, e de la otra parte tierra de las naranjas, / e de tierras de Doña Françisca e del camyno. /

(signo) Un corralejo que sale de unas casas de Eluira Sánchez, hija de / Diego Sánchez, çilurgano, que fueron del dicho Diego Sánchez, que ha / linderos una casa tyenda que es de vos los dichos Gonçalo Garçía e Bartolomé Sánchez, que ovistes conprado de Alfonso Garçía, pregonero, que ha / linderos el dicho corralejo, casas de la dicha Eluira Sánchez e de / casas tiendas de vos, los dichos compradores, e de casas tyenda de / Diego Sánchez de Baños. /

$<$ nuevo $>$ (signo) Un pedaço de tierras en que ay dos caballerías con la parte del Exido e / agua del Añorieta que les pertenesçee, que son en bogas. Que ha linderos / de la uparte tierras de herederos de Juan Garçía de Natera, e de la otra parte, / tyerras del dicho Juan Martínez, escrivano e de Catalina Sánchez, su / muger, e de tierras de las naranjas e del camino que fue de Alfonso / Díaz, jurado. /

72. [línea de cierre: Gonçalo / Román].

73. [línea de cierre: Gonçalo / Román]. 
(signo) Vna casa e tyenda e soberado que se compró de Diego ${ }^{74}$ de Tyneo / e de Beatriz Garçía, su muger, que es en la collaçión de Sant Dionis, que ha / linderos casas tiendas de los compradores e de casas de Diego Ferrández / de Milán, e de la calle. /

(signo) Los çient maravedís de tributo e çenso que de cada año, perpetuamente, es / obligado a dar e pagar Pedro Martínez Camacho, vezino en el Arrabal de / Santyago desta çibdad, que se ha de pagar por Sant Miguell del / mes de Setyenbre, perpetuamente, para siempre, por dos aran-/çadas de tierra que es a la serrana, término desta çibdat, en linde / de olivar de Bartolomé Gaytán, e de tierra e rosal de / axacafre, e de olivar de los dichos Bartolomé Sánchez e Gonçalo Garçía. /

(signo) E luego los dichos Bartolomé Sánchez e Gonçalo García, dixeron / que prometyan e prometyeron que los dichos bienes de suso decla-/rados por ellos nin por sus herederos nin deçendientes, que non / serían vendidos nin empeñados, nin cambiados, salvo que vsarían / dellos e de los frutos e rentas dellos, segund e como el dicho / Juan Martínez lo quiso e ordenó por el dicho su testamento, e $1 \mathrm{l}^{75} / / 3 \mathrm{rr}$. dicha Catalina Sánchez, su muger, lo confirmó e aprobó, e / de todo esto segund ante mi avía pasado pidieron a mi / el dicho Gonçalo Román, escriuano público, que ge lo diese por / testimonio en pública forma. E yo dile ende este firmado / del nonbre del dicho alcalde Diego Romi, e firmado de mi nombre, / e sygnado con mio sygno.

Testigos Ferrando de Orvaneja e Antón Franco, escrivanos del Rey, e Diego Sánchez e Alfonso / Martínez, escrivanos. /

Diego Romi, alcalde (rubricado). Antón Franco, escrivano del Rey (rubricado). Diego Sánchez, escrivano (rubricado). Ferrando de Orvaneja, escrivano del Rey (rubricado).

Yo Gonçalo Román, escrivano público de Xerez de la Frontera, lo fize escrivir e fiz aquí este / mio syg(signo)no. So testigo. /

En Granada a quynze días del mes de jullio de mill e quinientos e / çinquenta años, la presentó Antón Pérez en [...] de su parte con petición. //3v.

74. Repetido: de Diego.

75. [línea de cierre: Gonçalo / Román]. 
Anexo

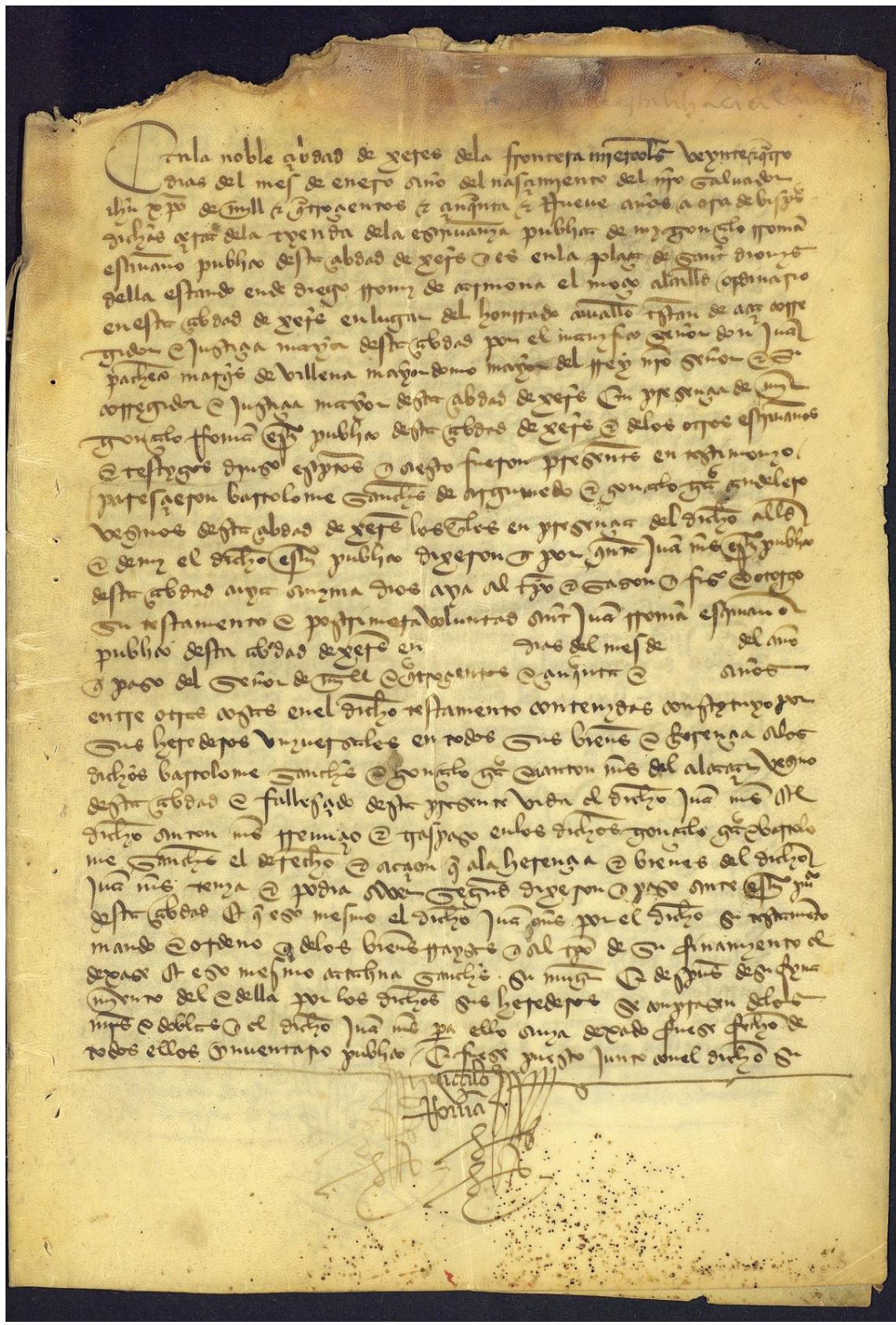

F. 1r. 


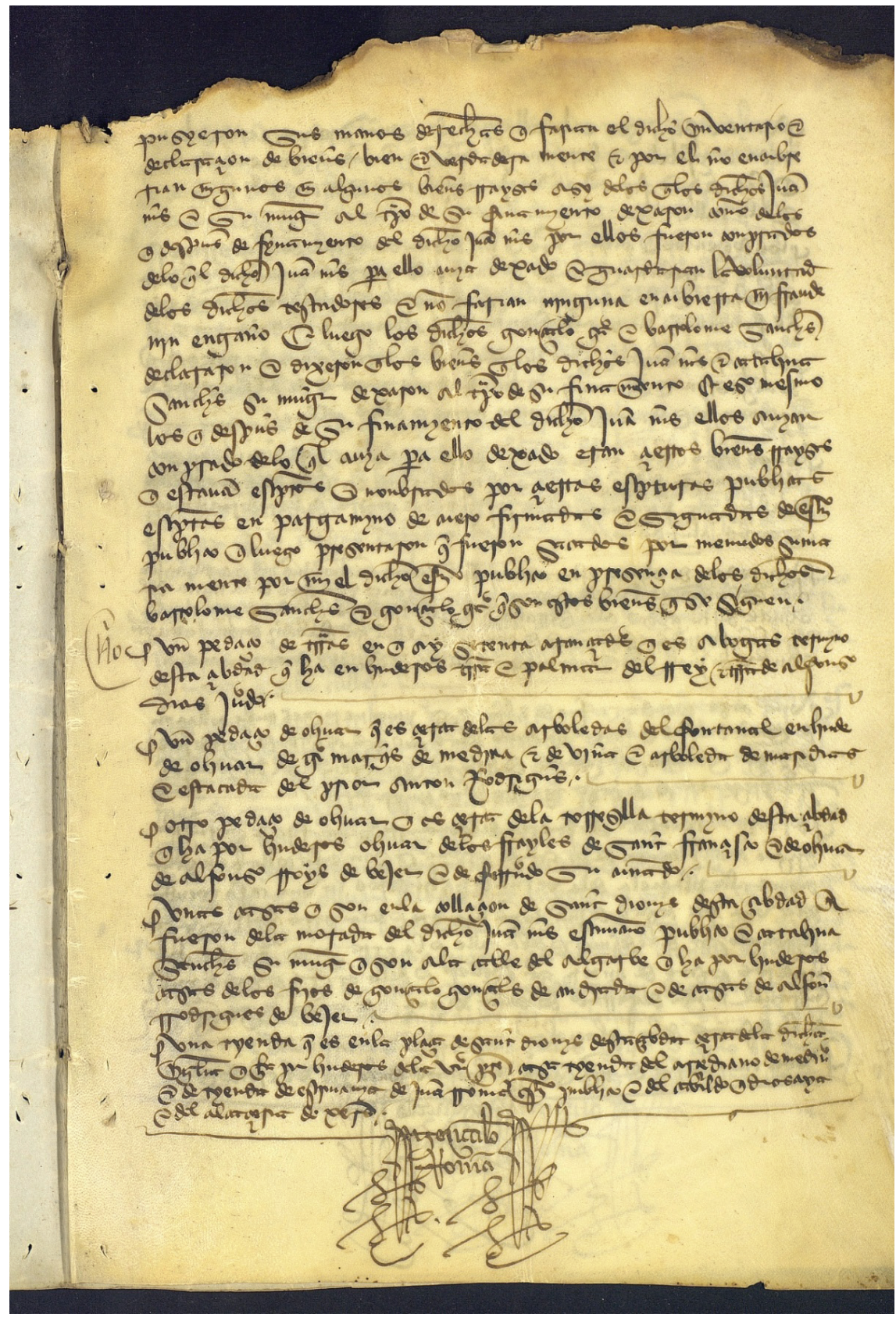

F. 2r. 


\section{BIBLIOGRAFÍA}

ABELLÁN PÉREZ, J. El concejo de Jerez de la Frontera en la primera mitad del siglo XV: composición, sistemas de elección y funcionamiento del cabildo, Jerez de la Frontera, 1990.

—, GARCÍA GUZMÁN, Ma . La religiosidad de los jerezanos según sus testamentos (siglo XV), Cádiz, 1997.

- Diplomatario del Reino de Granada. Documentos de Juan II de Castilla (1407-1454) del Archivo Municipal de Jerez de la Frontera, Universidad de Granada, 2011.

AGUADO DE LOS REYES, J. Riqueza y sociedad en la Sevilla del siglo XVII. Universidad de Sevilla, 1994.

ARRIBAS ARRANZ, F. "Los escribanos públicos en Castilla durante el siglo XV", Centenario de la Ley de Notariado. I: Estudios Históricos. Madrid, 1964, pp. 244-249.

CAÑADAS DE LA FUENTE, G. y otro. "Los Inventarios como fuente para la historia de las Ciencias de la Salud", III Jornadas de la Sociedad Española de Ciencias y Técnicas Historiográficas, Diplomática antigua. Diplomática moderna. Murcia, 20 y 21 de junio de 2005, pp. 257-266.

CARMONA RUIZ, Mª. y MARTÍN GUTIÉRREZ, E. Recopilación de las ordenanzas del concejo de Xerez de la Frontera. Siglos XV-XVI. Universidad de Cádiz, 2010.

CORRAL GARCÍA, E. El escribano de concejo en la Corona de Castilla (Siglos XI-XVIII). Burgos, 1987.

DEL CAMINO MARTÍNEZ, C. "La escritura de los escribanos públicos de Sevilla (1253-1300)", HID, 15. 1988, pp. 145-165.

—. "La escritura de la documentación notarial en la época colombina", en Tra Siviglia e Genova: Notaio, Documento e Commercio nell'Età Colombiana. Milán, 1994, pp. 485-50.

-. "La escritura de la documentación notarial en el siglo XIV", Cuadernos del Archivo Central de Ceuta, 15. 2006, pp. 29-56.

—. "Notarios y escritura ¿Un signo externo de distinción?” en MORENO TRUJILLO, A. y OSORIO PÉREZ J.M (Eds.) El Notariado andaluz. Institución, práctica notarial y archivos. Granada, 2011, pp. 109-232.

GUTIÉRREZ, B. Historia del estado presente y antiguo, de la mui noble y mui leal ciudad de Xerez de la Frontera. Xerez, 1886.

MÁRTIR ALARIO, Mª. Catálogo de la Colección de pergaminos del Archivo de la Real Chancillería de Granada. Junta de Andalucía, Consejería de Cultura, 2009.

OSTOS SALCEDO, P. “Los escribanos públicos de Córdoba en el tránsito de la Edad Media a la Edad Moderna. Una aproximación", El Notariado andaluz en el tránsito de la Edad Media a la Moderna. Sevilla, 1995, pp. 171-256. 
PARDO RODRÍGUEZ, M.L. "La escribanía mayor del concejo de Sevilla en la Edad Media", La Diplomatique urbaine en Europe en Moyen Âge. Garant, 2000, pp. 357-381.

RIESCO TERRERO, A. "Notariado y Documentación notarial castellano-leonesa de los siglos X-XIII”, I Jornadas sobre Documentación jurídico-administrativa, económico-financiera y judicial del reino castellano leonés (s. X-XIII). Madrid, febrero-marzo, 2002, p. 151.

-. Vocabulario científico-técnico de Paleografía, Diplomática y ciencias afines. Madrid, Barrezo \& Azedo Ediciones, 2003, p. 220.

—. "El Notariado castellano bajomedieval (siglos XIV-XV): Historia de esta institución y de la producción documental de los Notarios hasta el Reinado de Isabel I de Castilla", Segundas Jornadas cientificas sobre documentación de la Corona de Castilla (siglos XIII-XV). Madrid, 2003, pp. 175-224.

ROJAS VACA, MaD. "Notariado público y Documento Notarial en Jerez de la Frontera en el tránsito a la Modernidad”, El Notariado andaluz en el tránsito de la Edad Media a la Edad Moderna, I Jornadas sobre el Notariado en Andalucía. Sevilla, 1995, pp. 293-338.

—. "Los escribanos de concejo en Cádiz (1557-1607)", HID 24. Sevilla, 1997, pp. 429-448.

—. "Las escribanías del cabildo Municipal en Jerez de la Frontera (1514-1615)", HID 37. Sevilla, 2010, pp. 283-336.

RUIZ PILARES, E.J. “La formación de la oligarquía jerezana y la patrimonialización de los oficios concejiles (siglos XIII al XV)", en Revista de Historia de Jerez 16/17. 2010/2012, pp. 1-10.

SANZ FUENTES, Ma J. "Paleografía en la Baja Edad Media castellana", Anuario de Estudios Medievales, 21. 1991, pp. 520-545.

—. "La escritura gótica documental en la Corona de Castilla", en CALLEJA PUERTA, M., SANZ FUENTES, MaJ. (coords.) Paleografia II: las escrituras góticas desde 1250 hasta la imprenta. V Jornadas de la Sociedad Española de Ciencias y Técnicas Historiográficas, Oviedo, 18 y 19 de junio de 2007. Oviedo, 2010, pp. 107-126.

SOBRADO CORREA, H. "Los inventarios post-mortem", en Hispania LXIII/3, $n^{\circ} 215.2003$, pp. 825-862.

TOMÁS FACI, G., "Distinción social en el seno de la Baja Nobleza aragonesa. El palacio de los Zapata de Calatayud en 1984", Anuario de Estudios Medievales 39/2. Julio-Diciembre, 2009, pp. 605-629. http://dx.doi.org/10.3989/ aem.2009.v39.i2.117

Fecha de recepción del artículo: enero 2013

Fecha de aceptación y versión final: septiembre 2013 